\title{
Comparison of Physicochemical and Functional Properties of Chicken and Duck Egg Albumens
}

\section{-Author(s)}

\begin{tabular}{ll} 
Chaiyasit W' (D) https://orcid.org/0000-0003-4993-1917 \\
Brannan RG" \\
Chareonsuk D"I" & (D) https://orcid.org/0000-0003-0240-6373 \\
Chanasattru W"I & (D) https://orcid.org/0000-0002-4884-4160 \\
\hline
\end{tabular}

Division of Food Science and Technology, Faculty of Science and Technology, Thammasat University, Pathum Thani, 12120, Thailand

" School of Applied Health Science and Wellness, Ohio University, E170 Grover Center, Athens, OH 45701, United States.

III National Center for Genetic Engineering and Biotechnology, National Science and Technology Development Agency, Klong Luang, Pathum Thani, 12120, Thailand.

\begin{abstract}
The aim of this research was to investigate the physicochemical and functional properties of fresh and pasteurized chicken and duck egg albumens. The results showed that pasteurization of both chicken and duck albumens significantly decreased $(p \leq 0.05)$ viscosity, but had no impact ( $p>0.05$ ) on $\mathrm{pH}$ or free sulfhydryl groups. Chicken albumen was shown to have higher $(p \leq 0.05)$ foam expansion, but lower $(p \leq 0.05)$ foam stability than duck albumen. Pasteurization decreased $(p \leq 0.05)$ the foam expansion of both albumens while decreasing $(p \leq 0.05)$ the foam stability only of duck albumen. Investigation of the gel properties showed that duck albumen has greater hardness and lower expressible water $(p \leq 0.05)$ than chicken albumen. Pasteurization increased the hardness and decreased the expressible water of both the chicken and duck albumen gels. This study suggests that the superior gel properties of duck albumen offer potential approaches to improving the quality of gel food products.
\end{abstract}

\section{INTRODUCTION}

Eggs from chickens and ducks are two of the most consumed bird eggs in the world. Eggs are an excellent source of complete protein because they contain all of the essential amino acids (Abeyrathne et al., 2013; Gutierrez et al., 1997). They are considered high-cholesterol foods - $50 \mathrm{~g}$ of chicken and duck eggs contain as much as 200 and 450 $\mathrm{mg}$ of cholesterol, respectively - and public health recommendations often recommend limiting daily cholesterol levels to below $300 \mathrm{mg}$. However, recent studies suggest that consumption of a single chicken egg daily is not linked to an elevated risk of incident coronary heart disease (Virtanen et al., 2016). Eggs are also used as ingredients by the food industry in a wide array of commercial products (Mehdizadeh et al., 2015) because of their taste, nutritional value, and unique physicochemical properties such as water-holding capacity, oil binding, emulsification, foam formation, gelation and viscosity (Wu et al., 2009).

The egg albumen, also known as egg white, is compositionally similar in chickens and ducks ( $88 \%$ water and $11 \%$ protein) and has many functional properties. Two of the most important functional properties of the egg albumen are the ability to produce foam and to form heat-induced gels (Wang and Wang, 2009; Mehdizadeh et al., 2015). Foam formation and gelation affect both the texture and the sensory properties of the final food products. Foam formation is key for the production of meringues, bread, cookies, cakes, and several bakery products. Water-holding capacity of the egg albumen is related to its ability coagulate and link or bind with other ingredients (Mine, 1995) in products such as ham, sausages, surimi, and noodles (Hatta et al., 1997). However, the efficacy of these functional properties of the albumen are affected by intrinsic and extrinsic factors such as protein composition 
Chaiyasit W, Brannan RG, Chareonsuk D, Chanasattru W
Comparison of Physicochemical and Functional Properties of Chicken and Duck Egg Albumens and concentration, heating temperature, heating time, $\mathrm{pH}$, ionic strength, and the presence of other additives; therefore, different types of egg may exhibit different performance. The functional properties of the egg albumen are well-studied (Cunningham, 1995; Hatta et al., 1997; Plancken et al., 2005; Mine, 1995; Mehdizadeh et al., 2015); however, information about duck albumen functionality is much less common, especially in comparison with chicken albumen.

Pasteurization is required to destroy pathogens in the albumen but causes denaturation and aggregation of some egg proteins, resulting in impaired protein functionalities (Cunningham, 1995). Heating the albumen to the US standard pasteurization conditions of $55.6^{\circ} \mathrm{C}$ for $6.2 \mathrm{~min}$ or $56.7^{\circ} \mathrm{C}$ for $2 \mathrm{~min}$ is required to reduce the pathogenic bacterium Salmonella (Code of Federal Regulations, 2010). However, thermal processing causes some of proteins in the albumen to become denatured, affecting their function and making the albumen unsuitable as an ingredient in certain food products (Hou et al., 1996). A literature search revealed no previous studies that have investigated the functionality of pasteurized versus fresh albumen from duck and chicken eggs.

Chicken egg albumen is a common industrial food ingredient. Duck yolk is a common ingredient in Asian dishes and in the Thai dessert industry; however, duck albumen is a by-product and not currently used as a food ingredient in the food industry. The objective of this research was to compare the foaming and gelation properties of the albumen from fresh and pasteurized chicken and duck eggs. The information obtained in this study could provide guidelines for the utilization of duck albumen in the food industry.

\section{MATERIALS AND METHODS}

\section{Materials}

Four hundred fresh chicken eggs of Hisex Brown ${ }^{\circledR}$ hens between 31-32 wk of age and four hundred fresh duck eggs of Anas platyrhucus layers between 30-31 wk of age were collected from farms in Pathum Thani, Thailand. The eggs were kept at $28-32^{\circ} \mathrm{C}$ (normal egg storage conditions in Thailand) for less than three days.

Sodium dihydrogenphosphate and tri-sodium phosphate were purchased from Wako Pure Chemical Industries, Ltd. (Osaka, Japan). DTNB (5, 5'-dithiobis (2-nitrobenzoic acid)) and ANS- (1, 8-anilinonapthlensulfonate) were purchased from Sigma Aldrich (St. Louis, MO). Analytical grade hydrochloric acid and sodium hydroxide were purchased from Carlo Erba Reagents (Carlo Erba, Milan, Italy). All chemicals were used directly from the sample container without further purification. Distilled and de-ionized water was used for preparation of all buffer solutions. The $\mathrm{pH}$ of all buffer solutions used in this study was measured using a $\mathrm{pH}$ meter (SevenEasy ${ }^{\mathrm{T} M} \mathrm{pH}$ Meter S20, Mettler-Toledo, Schwerzenbach, Switzerland).

\section{Preparation of the Egg Albumen}

Forty eggs were randomly sampled, cleaned, and manually cracked, after which the albumen was separated and collected. The albumen was placed in an ice bath and maintained at $0^{\circ} \mathrm{C}$ for $30 \mathrm{~min}$. The albumen was transferred into a $50 \mathrm{~mL}$ syringe then injected through a 60-mesh stainless sieve screen to remove large particles. The screening was repeated three times within 20 min to ensure the homogeneity of the sample. The albumen was kept in the ice bath until further use. Three sets of chicken or duck egg albumens were separately prepared, and the albumens were separately used for further experiments.

\section{Preparation of Pasteurized Egg Albumen}

Two hundred grams of the albumen were transferred to a $400-\mathrm{mL}$ beaker, and then equilibrated to $30^{\circ} \mathrm{C}$ using a water bath. After the temperature of the sample reached $30^{\circ} \mathrm{C}$, the beaker containing the albumen was transferred to a $66^{\circ} \mathrm{C}$ water bath. The albumen was equilibrated with stirring at $1300 \mathrm{rpm}$ (IKA, C-MAG MS 7, Germany). After the temperature reached $56.5^{\circ} \mathrm{C}$, the beaker was transferred to a $56.5 \pm$ $1.0^{\circ} \mathrm{C}$ water bath. The albumen was further incubated with stirring at $1300 \mathrm{rpm}$ for $3.5 \mathrm{~min}$ then put into an ice bath with stirring at the same speed for $10 \mathrm{~min}$.

\section{Proximate Analysis}

Proximate analysis such as moisture, ash, crude fat, fiber and protein contents were determined using the methods of AOAC (2000). The carbohydrate content was calculated by subtraction from the other contents.

\section{Determination of Haugh Units}

The Haugh unit was used to determine egg freshness, as described by Haugh (1937). Forty eggs were sampled to measure the Haugh unit, which value was calculated as follows:

$$
\text { Haugh unit }=100 \log \left(h-1.7 w^{0.37}+7.57\right)
$$

Where:

$\mathrm{h}=$ Observed albumen thickness ( $\mathrm{mm}$ )

$w=$ Weight of the entire egg $(g)$ 
Chaiyasit W, Brannan RG, Chareonsuk D, Chanasattru W
Comparison of Physicochemical and Functional Properties of Chicken and Duck Egg Albumens

\section{Determination of Physical Properties}

Albumen $\mathrm{pH}$, density, viscosity and solid content were determined by $\mathrm{pH}$ meter (SevenEasy ${ }^{\mathrm{TM}} \mathrm{pH}$ Meter S20, Mettler-Toledo, Schwerzenbach, Switzerland), pycnometer (Wilmad-LabGlass, USA), Brookfield viscometer equipped with RV1 spindle (Eng Labs DE33009, USA) and moisture balance (Satorius MA30, Germany), respectively. For density and viscosity, samples were performed at $25^{\circ} \mathrm{C}$.

\section{Determination of Exposed Free-Sulfhydryl Groups of Protein}

The influence of pasteurization on the exposed free sulfhydryl (SH) groups of the albumen was measured using Ellman's reagent [5, 5'-dithiobis (2-nitrobenzoic acid)] or DTNB, as described by Beveridge and others (1974) with some modification. Briefly, albumen was equilibrated at room temperature for $1 \mathrm{~h}$. One milliliter of albumen was suspended in $9 \mathrm{~mL}$ of distilled water then vortexed for $10 \mathrm{~s}$. Five hundred microliters of the mixture were diluted with $500 \mu$ l of standard buffer $\mathrm{pH}$ 8.0 (containing $86 \mathrm{mM}$ trisaminomethane (TRIS), 90 $\mathrm{mM}$ glycine and $4 \mathrm{mM}$ ethylenediaminetetraacetic acid (EDTA)). Ten microliters of Ellman's reagent solution (4 $\mathrm{mg}$ of $\mathrm{DTNB} / \mathrm{mL}$ of standard buffer) were added to the mixed solution then allowed to incubate at room temperature for $1 \mathrm{~h}$. The mixture was centrifuged at $13,000 \times \mathrm{g}, 20^{\circ} \mathrm{C}$ for $20 \mathrm{~min}$. The supernatant was collected to determine the exposed free sulfhydryl group content. Absorbance was recorded at 412 nm using a UV-Vis spectrophotometer (Helios Alpha, Thermo Electron Corporation, England). The standard buffer was used as blank. The free sulfhydryl groups ( $\mu$ mole SH/g protein) of each sample were calculated using a molar extinction coefficient of $1.36 \times 10^{4} \mathrm{M}^{-1}$ $\mathrm{cm}^{-1}$. All measurements were done on three freshly prepared samples.

\section{Determination of Surface Hydrophobicity of Protein}

The surface hydrophobicity $\left(S_{0}\right)$ of the chicken and duck albumen was determined using 1, 8-anilinonapthalenesulfonate (ANS-) as described by Haskard and Li-Chan (1998). ANS- stock solution (8 $\mathrm{mM}$ ) was prepared by dissolving ANS- in $10 \mathrm{mM}$ of phosphate buffer $(\mathrm{pH}$ 7.0). The protein content of albumen was determined by Lowry's method using bovine serum albumin (BSA) as a standard (Lowry et al., 1951). Egg white protein suspensions of 0.20-0.50 $\mathrm{mg}$ protein $/ \mathrm{mL}$ were prepared in $10 \mathrm{mM}$ of phosphate buffer $\mathrm{pH}$ 7.0. Four milliliters of diluted protein suspension were mixed with $20 \mu \mathrm{l}$ of ANS stock solution and vortexed for $5 \mathrm{~s}$. The fluorescence intensity (FI) of the mixtures was measured at an excitation wavelength at $370 \mathrm{~nm}$ and emission wavelength at $470 \mathrm{~nm}$ using a microplate reader (Infinite M200 PRO, TECAN Austria $\mathrm{GmbH}$, Austria). The Fl of each sample was calculated by subtracting the $\mathrm{Fl}$ of the buffer. The $\mathrm{S}_{0}$ was the initial slope of the subtracted $\mathrm{Fl}$ versus the protein concentration calculated by linear regression analysis.

\section{Determination of Molecular Weight of Protein}

The molecular weight of the protein samples was determined as described by Laemmli (1970). Briefly, sodium dodecyl sulfate polyacrylamide gel electrophoresis (SDS-PAGE) was performed on a discontinuous buffer system with and without $\beta$-mercaptoethanol using $12.5 \%$ separating gel and $4 \%$ stacking gel. Protein samples in loading buffer (containing $0.0625 \mathrm{M} \mathrm{TRIS}-\mathrm{HCl}, 10 \%$ glycerin, 2\% SDS, $0.0025 \%$ bromophenol blue, and with or without $5 \% \quad \beta$-mercaptoethanol) were loaded into the gel $(10 \mu \mathrm{g}$ of protein/well). Gel electrophoresis was performed at $20 \mathrm{~mA}$ for $90 \mathrm{~min}$. Gel was stained with Coomassie Brilliant Blue G-250 and destained in a destaining solution (30\% methanol, 10\% acetic acid and $60 \%$ distilled water) prior to gel imaging. The protein content in the sample was determined using the method described in the previous section for proximate analysis.

\section{Determination of Foaming Properties}

The foaming properties of the chicken and duck albumens as well as the effect of pasteurization on the foaming properties were analyzed as described by Uzun and others (2012) with some modifications. The albumen was equilibrated to room temperature for 1 h. One hundred milliliters of albumen were transferred into a stainless steel bowl (Seagull, Thai Stainless Steel Co., Ltd., Thailand) $21 \mathrm{~cm}$ in diameter and $8.5 \mathrm{~cm}$ in height, then whipped with a hand blender (HM-009 OTTO, Otto King Glass Co., Ltd., Thailand) at speed 5 (speed 1-slowest and speed 5-fastest) for $3 \mathrm{~min}$. The height of the foam was measured directly using Vernier caliper at five different locations of the foam and the average height was used to calculate the volume of foam. The liquid drainage of the foam at various times (0-120 min) was collected and weighed. Foam expansion and foam stability as a percentage of drainage were calculated as follow: 
Chaiyasit W, Brannan RG, Chareonsuk D, Chanasattru W
Foam expansion $(\%)=[$ Volume of foam/Volume of liquid egg albumen] $\times 100$

Drainage $(\%)=[$ Weight of liquid drainage at specific time/Weight of liquid egg albumen] ×100

\section{Determination of Gel Hardness}

The hardness of the gels and the influence of pasteurization on the hardness of the gels were studied using a method adapted from Harkouss and others (2015). Albumen was equilibrated to room temperature. Twenty milliliter of the albumen was poured into $2.5 \mathrm{~cm}$ diameter plastic casing. The casings were sealed at both ends then boiled for $15 \mathrm{~min}$ in a water bath (Boiling-Sterilizer, Applied Medic Ltd., Thailand). Samples were then immediately cooled in an ice bath for $5 \mathrm{~min}$ and stored at $4^{\circ} \mathrm{C}$ overnight. Gel samples were equilibrated to room temperature (about $25^{\circ} \mathrm{C}$ ) for $1 \mathrm{~h}$ and removed from the plastic casing then cut into $1.5 \times 1.5 \times 2.0 \mathrm{~cm}^{3}$ (width $\times$ length $\times$ height) bricks. Texture profile analysis (TPA) of the protein gels was performed using a texture analyzer (TA XT2i Texture Analyzer, Stable Micro Systems, England) equipped with a $50 \mathrm{~mm}$ diameter aluminum cylinder probe (P50) and a $20 \mathrm{~kg}$ load cell. Measurements were performed at a crosshead speed of $5.0 \mathrm{~mm} / \mathrm{s}$ until a maximum Cauchy strain of 0.5 was reached (Woodward \& Cotterill, 1986). Only gel hardness is reported in this paper.

\section{Determination of Expressible Moisture}

The percentage of expressible water from the egg white gel was determined using a procedure adapted from Funami and others (1998). The expressible water was calculated from the moisture loss after compression. Egg white gels were cut into $1.5 \times 1.5$ $\times 2.0 \mathrm{~cm}^{3}$ (width $\times$ length $\times$ height) bricks, placed between double layers of filter paper (Whatman No. 4) and then compressed using a texture analyzer at a crosshead speed of $3 \mathrm{~mm} / \mathrm{s}$ to $70 \%$ strain for $60 \mathrm{~s}$ with a cylindrical aluminum probe (50 $\mathrm{mm}$ diameter). One gram of samples both before and after compression was sampled to measure the moisture content using a moisture analyzer (MA 30, Sartorius, Germany). The expressible moisture content was calculated from the following equation:

Expressible water $(\%)=100 \times\{$ (Total moisture content of gel - moisture content after compression of gel)/(Total moisture content of gel)\}

\section{Determination of Egg White Gel Color}

The color of the egg white gel was determined using a Chroma meter (CR-300, Minolta Co., Ltd.,
Japan) from the mean value of three measurements. Egg white gels were cut into $1.5 \times 1.5 \times 2.0 \mathrm{~cm}^{3}$ (width $\times$ length $\times$ height) bricks. The color was reported in the CIE Lab color system. The Chroma meter was calibrated using a Minolta calibration plate.

\section{Statistical Analysis}

Experiments were done in triplicate using freshly prepared samples. Statistical analysis was performed using one-way analysis of variance (ANOVA) (Cochran and Cox, 1992) using SPSS version 11.5 (SPSS Inc., Chicago, USA). Mean separation were achieved using Duncan's multiple range test at a 95\% confidence level.

\section{RESULTS AND DISCUSSION}

\section{Physicochemical Properties of Fresh Chicken and Duck Albumens}

Since freshness is an important parameter related to protein function in egg, Haugh unit (HU) was determined for both chicken and duck eggs (Haugh, 1937). Because HU of duck eggs may be affected by the fact that duck eggs are commonly bigger and can have a different proportion of albumen, $\mathrm{HU}$ in this investigation was only used to control and report the freshness of each egg: the higher the number, the better the quality of the egg. The average $\mathrm{HU}$ values of chicken and duck eggs used in this study were $75.31 \pm 7.13$ and $66.28 \pm 3.63$, respectively. $\mathrm{HU}$ values of 72 or higher for chicken eggs are used by the USDA to indicate AA quality grade, indicating that the egg is fresh and the albumen is sufficiently thick. However, there is no standard for duck eggs. In this experiment, duck eggs had lower HU value than chicken eggs, even though both chicken and duck eggs used were stored for the same duration and under the same conditions.

The results from the proximate analysis are shown in Table 1. No significant difference between chicken and duck albumens was found for fat, ash, or fiber contents. The chicken albumen had a significantly higher $(p \leq 0.05)$ moisture content than the duck albumen, but lower $(p \leq 0.05)$ carbohydrate and protein contents. The protein content was 12.15 $\pm 0.08 \%$ for duck albumen and $10.03 \pm 0.08 \%$ for chicken albumen. A similar result in chicken albumen was reported by Alamprese et al. (2012), who found that the protein content of chicken albumen was 9.9$11.3 \%$. 
Table 1 - Proximate analysis (mean \pm standard deviation) of duck and chicken egg albumens.

\begin{tabular}{lcc}
\hline & Duck Albumen & Chicken Albumen \\
\hline Moisture & $86.19 \pm 0.10^{\mathrm{b}}$ & $88.48 \pm 0.05^{\mathrm{a}}$ \\
Protein & $12.15 \pm 0.08^{\mathrm{a}}$ & $10.03 \pm 0.08^{\mathrm{b}}$ \\
Crude Fat & $0.03 \pm 0.01$ & $0.01 \pm 0.00$ \\
Carbohydrate & $0.91 \pm 0.02^{\mathrm{a}}$ & $0.75 \pm 0.04^{\mathrm{b}}$ \\
Ash & $0.72 \pm 0.03$ & $0.73 \pm 0.00$ \\
Fiber & $0.00 \pm 0.00$ & $0.00 \pm 0.00$ \\
\hline
\end{tabular}

$\mathrm{a}, \mathrm{b}$ Different letters in the same row indicate significant differences between means $(p \leq 0.05)$.

Table 2 shows the physical properties of chicken and duck albumen. The density and $\mathrm{pH}$ of the chicken and duck albumens were not significantly different $(p>0.05)$. The viscosity of the duck albumen was significantly lower $(p \leq 0.05)$ than that of the chicken albumen, while the solid content of the duck albumen significantly higher $(p \leq 0.05)$ than that of the chicken albumen. Pasteurization significantly decreased $(p \leq 0.05)$ the viscosity of both. The viscosity decreased from $7.18 \pm 0.08$ to $3.87 \pm 0.05 \mathrm{cP}$ in the chicken albumen and from $6.25 \pm 0.05$ to $5.70 \pm 0.09 \mathrm{cP}$ in the duck albumen. Heat from the pasteurization may denature some proteins in the albumen, leading to protein aggregation. For example, denaturation of ovotransferrin, the most heat sensitive protein in the albumen, occurs between $53^{\circ} \mathrm{C}$ and $65^{\circ} \mathrm{C}$ (Mine, 1995; Lomakina \& Mikova, 2006). Thus, heat treatment could change the ovotransferrin from native to denatured form, altering the viscosity of the albumen. Nicoud and coworkers (2015) found that in some proteins the viscosity of an aggregate sample was lower than that of a monomeric sample of a similarly-occupied volume fraction due to the polydispersity of the aggregate distribution. In addition, the shear forces used in heat treatment may disrupt high molecular weight complexes such as ovomucin in thick albumen (Lang \& Rha, 1982). This could be another reason that pasteurization caused the viscosity to decrease.

Table 2 - Density, pH, viscosity, solid content, free sulfhydryl group content, and surface hydrophobicity (mean \pm standard deviation) of fresh and pasteurized duck and chicken egg albumens.

\begin{tabular}{lcccc}
\hline & \multicolumn{2}{c}{ Duck Albumen } & \multicolumn{2}{c}{ Chicken Albumen } \\
Property & Fresh & Pasteurized & Fresh & Pasteurized \\
\hline Density $(\mathrm{g} / \mathrm{mL})$ & $1.0357 \pm 0.0375$ & $1.0361 \pm 0.0462$ & $1.0327 \pm 0.0004$ & $1.0337 \pm 0.0000$ \\
$\mathrm{pH}$ & $9.03 \pm 0.01$ & $9.04 \pm 0.01$ & $9.05 \pm 0.11$ & $9.07 \pm 0.01$ \\
Viscosity $(\mathrm{cP})$ & $6.25 \pm 0.05^{\mathrm{b}}$ & $5.70 \pm 0.09^{\mathrm{c}}$ & $7.18 \pm 0.08^{\mathrm{a}}$ & $3.87 \pm 0.05^{\mathrm{d}}$ \\
Solid Content $(\%)$ & $13.47 \pm 0.11^{\mathrm{a}}$ & $13.74 \pm 0.29^{\mathrm{a}}$ & $11.49 \pm 0.06^{\mathrm{b}}$ & $11.74 \pm 0.11^{\mathrm{b}}$ \\
Free sulfhydryl group $(\mu \mathrm{mol} / \mathrm{g}$ protein) & $2.63 \pm 0.51^{\mathrm{a}}$ & $2.26 \pm 0.12^{\mathrm{a}}$ & $0.48 \pm 0.00^{\mathrm{b}}$ & $0.33 \pm 0.06^{\mathrm{b}}$ \\
Surface hydrophobicity $\left(\mathrm{S}_{0}\right) \times 10^{4}$ & $3.85 \pm 0.03^{\mathrm{c}}$ & $6.25 \pm 0.17^{\mathrm{b}}$ & $3.97 \pm 0.08^{\mathrm{c}}$ & $8.13 \pm 0.24^{\mathrm{a}}$ \\
\hline
\end{tabular}

$a, b, c, d$ Different letters in the same row indicate significant differences between means $(p \leq 0.05)$.

\section{SDS-PAGE Patterns of Chicken and Duck Albumen Proteins}

The molecular weight of chicken and duck albumen proteins was determined by SDS-PAGE, shown in Figure 1. The results show that the SDS-PAGE pattern of duck albumen was different from that of chicken both in the presence and absence of a reducing agent. These results indicate that the protein composition of the duck and chicken albumens was different. For SDS-PAGE without the reducing agent, duck albumen had lower lysozyme (Mw 14 kDa (Mine, 1995)) and ovotransferrin (Mw $\sim 76 \mathrm{kDa}$ (Mine, 1995)) contents, but higher ovomucin (Mw 254 kDa for a carbohydrate-poor $\alpha$-ovomucin and $\mathrm{Mw} \sim 400-610 \mathrm{kDa}$ for a carbohydrate-rich $\beta$-ovomucin (Offengenden et al., 2011)) contents. It should be noted that the ovomucoid (Mw $28 \mathrm{kDa}$ ) (Mine, 1995) of the chicken albumen appeared at 30 to $40 \mathrm{kDa}$ in SDS-PAGE profiles, possibly because the band could not be separated from the ovalbumin band (a major albumen protein and $\mathrm{Mw} \sim 45 \mathrm{kDa}$ ) (Mine, 1995). In addition, a related band with higher molecular weight also appeared on the duck albumen profile. Similar results were found in SDS-PAGE with a reducing agent in both chicken and duck albumens. The results also indicated that a heat process in which the temperature was raised to $56.5^{\circ} \mathrm{C}$ then held for $3.5 \mathrm{~min}$ did not lead to detectable levels of protein aggregation on the SDS-PAGE patterns of chicken or duck albumen, as shown in Figure 1.

\section{Free Sulfhydryl Content in Chicken and Duck Albumen Proteins}

The purpose of this experiment was to compare the exposed free sulfhydryl groups of the two egg albumens and to study the influence of pasteurization on the free sulfhydryl content. Table 2 shows the free sulfhydryl group content of both the pasteurized and non-pasteurized albumens. The free sulfhydryl groups of the non-pasteurized duck albumen were 
Chaiyasit W, Brannan RG, Chareonsuk D, Chanasattru W
Comparison of Physicochemical and Functional
Properties of Chicken and Duck Egg Albumens

albumen had a significantly higher $(p \leq 0.05)$ foam expansion than the duck albumen. Foam expansion of non-pasteurized chicken albumen was $811 \pm 56 \%$ and that of the duck albumen was $626 \pm 75 \%$. Foam is a colloidal system with a solid continuous phase trapping air. Foam stability depends on the ability of a protein to adsorb and form a protective membrane at liquid-air interface. This result suggests that chicken albumen forms more stable liquid-air film than that of ducks. Pasteurization lowered the foam expansion of both chicken and duck albumens, indicating that pasteurization decreased membrane strength at the liquid-air interface. These results could be explained by excessive protein denaturation caused by the heat treatment, reducing the foam formation ability of the protein. Denatured proteins may be less able to form the two-phase colloidal system and trap air than partially denatured proteins. Pasteurization had a stronger impact on duck albumen, decreasing foam expansion by nearly $41 \%$, compared with approximately $18 \%$ for the chicken albumen.

Figure 2 shows the relationship between foam drainage and incubation time in non-pasteurized and pasteurized albumens. The weight of the drainage from albumen increased over time. It should be noted that lower drainage indicates higher foam stability. Non-pasteurized duck albumen had lower $(p \leq 0.05)$ drainage than non-pasteurized chicken albumen, giving it higher foam stability $(p \leq 0.05)$. This suggests that the membrane produced by the duck albumen was stronger than that of the chicken albumen. Pasteurization had an impact on the drainage of both albumens. While pasteurization significantly $(p \leq 0.05)$ increased the foam stability of the chicken albumen, the opposite was found for the duck albumen. These results could be explained by the strength of the film that trapped and separated the air bubbles after heat treatment, and suggest that it increased in the chicken albumen, but decreased in the duck albumen. Shown in Table 3, the drainage recorded after $1 \mathrm{~h}$ of foam storage indicated foam stability in the following order: pasteurized chicken albumen > non-pasteurized duck albumen $>$ pasteurized duck albumen $>$ nonpasteurized chicken albumen. Pasteurization changed

\section{Foam Capacity and Foam Stability}

Foam expansion is an important functional property of the egg albumen. Table 3 shows that the chicken

Table 3 - Expansion and drainage at $1 \mathrm{~h}$ (mean \pm standard deviation) of foams prepared from fresh and pasteurized duck and chicken egg albumens.

\begin{tabular}{|c|c|c|c|c|}
\hline & \multicolumn{2}{|c|}{ Duck Albumen } & \multicolumn{2}{|c|}{ Chicken Albumen } \\
\hline & Fresh & Pasteurized & Fresh & Pasteurized \\
\hline Foam Expansion (\%) & $626 \pm 75^{b}$ & $370 \pm 5^{c}$ & $811 \pm 56^{a}$ & $668 \pm 37^{b}$ \\
\hline Foam Drainage at $1 \mathrm{~h}(\%)$ & $38.0 \pm 0.6^{c}$ & $46.9 \pm 0.5^{b}$ & $52.7 \pm 1.2^{a}$ & $34.3 \pm 1.5^{d}$ \\
\hline
\end{tabular}

$a, b, c, d$ Different letters in the same row indicate significant differences between means $(p \leq 0.05)$. 
Chaiyasit W, Brannan RG, Chareonsuk D, Chanasattru W
Comparison of Physicochemical and Functional Properties of Chicken and Duck Egg Albumens the drainage of duck albumen from $38.0 \pm 0.6$ to 46.9 $\pm 0.5 \%$ and chicken albumen from $52.7 \pm 1.2$ to 34.3 $\pm 1.5 \%$.

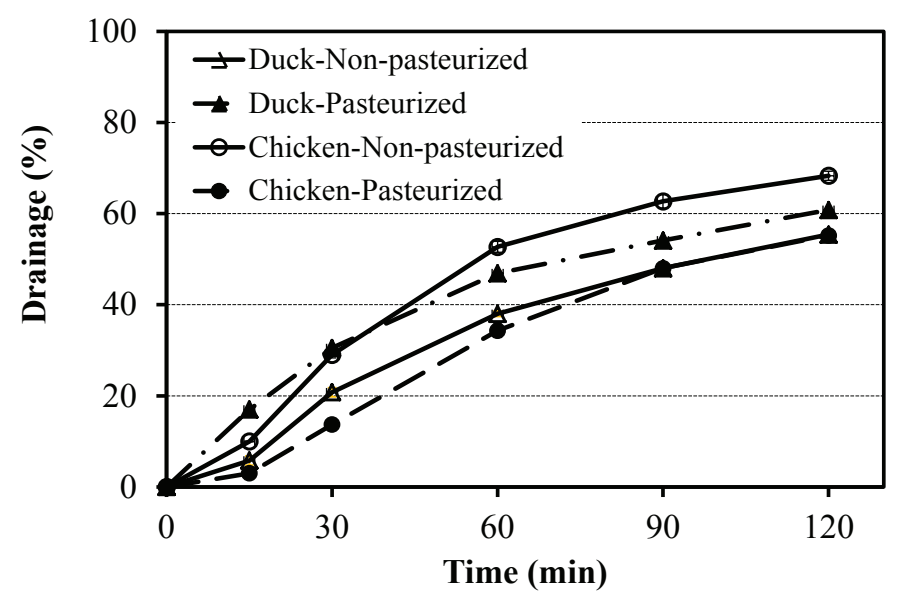

Figure $\mathbf{2}$ - Influence of pasteurization on drainage of chicken and duck egg albumen from 0 to $120 \mathrm{~min}$.

\section{Gel Properties and Expressible Water}

Gel formation is another important functional property of the egg white protein. Table 4 shows the hardness of the gels prepared from non-pasteurized and pasteurized duck and chicken albumens. The non-pasteurized duck albumen gel had significantly $(p \leq 0.05)$ higher gel hardness than the non-pasteurized chicken albumen gel. These results may be attributed to the free sulfhydryl and protein contents of the albumens. Our results showed that the free sulfhydryl content of duck albumen was higher than that of chicken albumen both with and without pasteurization (Table 2). Proteins with free sulfhydryl groups form gels with higher gel hardness than proteins without free sulfhydryl groups as these free sulfhydryl groups are key in heat-induced gelation and the determination of gel strength (Zayas, 1997). During heat treatment, the free sulfhydryl groups form covalent disulfide bonds resulting in a protein gel with high hardness. In this study, pasteurization significantly increased $(p \leq 0.05)$ gel hardness of the duck albumen but had no impact ( $p>0.05)$ on the gel hardness of chicken albumen, as shown in Table 4. Pasteurization increased gel hardness of the duck albumen from $19.20 \pm 0.88$ to $23.60 \pm$ $0.41 \mathrm{~N}$.

Table 4 shows that the duck albumen gel contained significantly lower $(p \leq 0.05)$ expressible water than the chicken albumen gel. The expressible water of non-pasteurized duck and chicken albumen gels were $5.49 \pm 0.43$ and $6.43 \pm 0.49 \%$, respectively. These results suggest that the duck albumen gel trapped water inside the 3-dimensional gel structure more strongly than the chicken albumen gel. Pasteurization significantly decreased $(p \leq 0.05)$ expressible water in both gels, by $5.49 \pm 0.43$ to $4.05 \pm 0.09 \%$ in ducks and $6.43 \pm 0.49$ to 5.64 $\pm 0.12 \%$ in chickens. These results suggest that pasteurized albumen gel trapped water better than non-pasteurized albumen gel.

Table 4 shows the CIE Lab color of the heatinduced gels prepared from both non-pasteurized and pasteurized duck and chicken albumens. Compared with chicken gels, duck gels were significantly darker (lower $\left.L^{*}\right)$, less green (lower $\left.-a^{*}\right)$, slightly blue $\left(-b^{*}\right)$ than chicken gels, which were slightly yellow $\left(+b^{*}\right)$. Pasteurization had no impact on the CIE Lab attributes shown in Table 4.

\section{SUMMARY}

While side-by-side comparisons of chicken and duck meat have been made, here we report the first comparison of the functional properties of chicken and duck albumen. Overall, duck albumen contains more protein than chicken albumen, probably due to ovomucin. Duck albumen is less viscous than chicken albumen. Duck albumen has more exposed sulfhydryl groups, but its surface hydrophobicity is not different from chicken albumen. Duck albumen foams exhibited less expansion, but higher foam stability than chicken albumen foams. Duck albumen gels were harder and exhibited less expressible water than chicken albumen gels, and were darker.

Table 4 - Hardness, expressible water, and color (mean \pm standard deviation) of heat-induced gels prepared from fresh and pasteurized duck and chicken egg albumens.

\begin{tabular}{|c|c|c|c|c|}
\hline & \multicolumn{2}{|c|}{ Duck Albumen } & \multicolumn{2}{|c|}{ Chicken Albumen } \\
\hline & Fresh & Pasteurized & Fresh & Pasteurized \\
\hline Gel Hardness (N) & $19.20 \pm 0.88^{b}$ & $23.60 \pm 0.41^{a}$ & $12.09 \pm 0.54^{c}$ & $13.40 \pm 0.27^{c}$ \\
\hline Expressible Water (\%) & $5.49 \pm 0.43^{b}$ & $4.05 \pm 0.09$ & $6.43 \pm 0.49^{a}$ & $5.64 \pm 0.12^{b}$ \\
\hline$L^{*}$ & $77.86 \pm 0.36^{b}$ & $77.27 \pm 1.60^{b}$ & $83.66 \pm 0.43^{a}$ & $83.00 \pm 1.20^{a}$ \\
\hline$a^{*}$ & $-3.57 \pm 0.02^{b}$ & $-3.42 \pm 0.25^{b}$ & $-5.71 \pm 0.06^{a}$ & $-5.33 \pm 0.50^{a}$ \\
\hline$b^{*}$ & $-1.57 \pm 0.36^{b}$ & $-1.03 \pm 0.28^{b}$ & $3.88 \pm 0.63^{a}$ & $4.63 \pm 0.70^{a}$ \\
\hline
\end{tabular}

$a, b, c, d$ Different letters in the same row indicate significant differences between means $(p \leq 0.05)$. 
Chaiyasit W, Brannan RG, Chareonsuk D, Chanasattru W
Comparison of Physicochemical and Functional Properties of Chicken and Duck Egg Albumens
It is not known how the sensory properties of egg albumen from duck differs from chicken, but culinary applications for gels and foams from duck albumen could replace chicken albumen for applications, where firmness and syneresis control would be desirable such as egg tofu, and egg loaf. There are many other food and non-food related industrial applications typically reserved for chicken albumen that may be filled by duck albumen.

\section{CONCLUSIONS}

Overall, our results demonstrated differences in the physicochemical and protein functionalities of duck and chicken albumen (as shown in Figure 3), especially foaming and gelling properties. Chicken albumen was shown to exhibit superior foam properties relative to duck albumen, whereas duck albumen had superior gel properties, including lower expressible water. These findings could be used to improve the quality of foaming and gelling food products. Our research also suggests potential uses for the duck albumen that is produced as a by-product in the Thai dessert industry and many Asian cuisines, which is currently sometimes discarded. This offers both economic and environmental benefits.

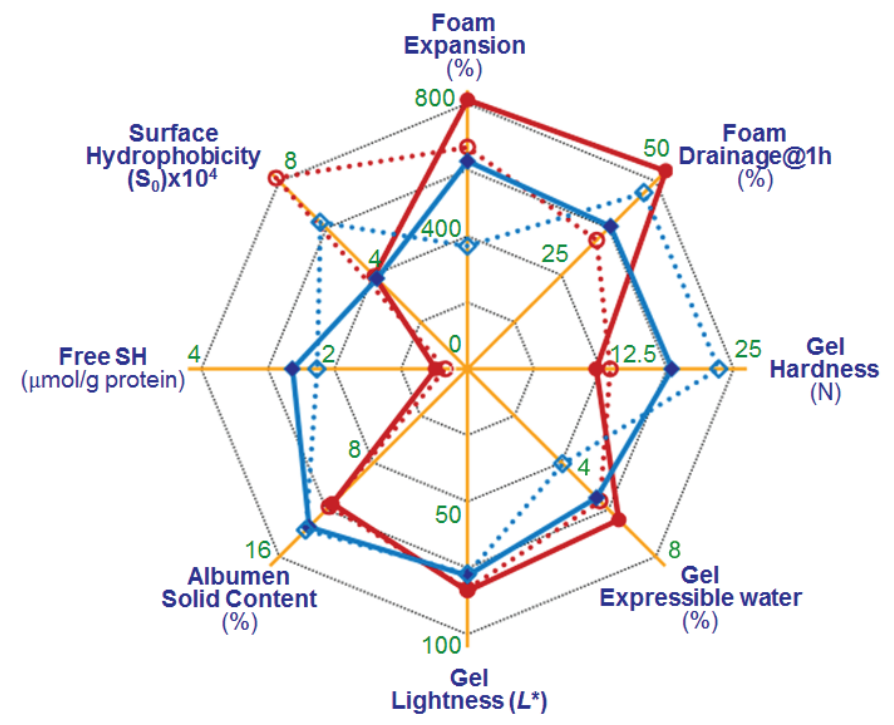

$\longrightarrow$ Fresh Chicken Egg White —— Fresh Duck Egg White

… Pasteurized Chicken Egg White … .. Pasteurized Duck Egg White

Figure 3 - Comparison of physicochemical and functional properties of chicken and duck egg albumens.

\section{ACKNOWLEDGEMENT}

The authors gratefully acknowledge the financial support partially provided by the Higher Education Research Promotion and National Research University
Project of Thailand, Office of the Higher Education Commission.

\section{REFERENCES}

Abeyrathne EDNS, Leel HY, Ahn DU. Egg white proteins and their potential use in food processing or as nutraceutical and pharmaceutical agents-A review. Poultry Science 2013;92:3292-3299.

Alamprese C, Casiraghi E, Rossi M. Foaming, gelling and rheological properties of egg albumen as affected by the housing system and the age of laying hens. International Journal of Food Science and Technology 2012;47:1411-1420.

AOAC. Official methods of analysis of AOAC International. 17 th $\mathrm{ed}$. Washington: Association of Official Analytical Chemists; 2000.

Beveridge T, Toma SJ, Nakai S. Determination of SH- and SS- groups in some food proteins using Ellman's Reagent. Journal of Food Science 1974;39:49-51.

Cochran WG, Cox GM. Experimental designs, 2nd ed. New York: Wiley; 1992.

Code of Federal Regulations. Title 9-Animals and animal products [section 590.570]. pasteurization of liquid eggs [cited 2014 Mar 7]. 2010. Available from: http://www.gpo.gov/fdsys/pkg/CFR-2010-title9-vol2/ pdf/CFR-2010-title9-vol2-sec590-570.pdf.

Cunningham FE. Egg-product pasteurization. In: Stadelman WJ, Cotterill OJ. Egg science and tTechnology. $4^{\text {th }}$ ed. Binghampton: Hawthorn Press; 1995. p.289-321.

Funami T, Yada H, Nakao Y. Thermal and rheological properties of curdlan gel in minced pork gel. Food Hydrocolloids 1998;12:55-64.

Gutierrez MA, Takahashi H, Juneja LR. Nutritive evaluation of hen eggs. In: Yamamoto T, Juneja LR, Hatta H, Kim M. Hen eggs: their basic and applied science. Boca Raton: CRC Press; 1997. p.25-35.

Harkouss R, Astruc T, Lebert A, Gatellier P, Loison O, Safa H, et al. Quantitative study of the relationships among proteolysis, lipid oxidation, structure and texture throughout the dry-cured ham process. Food Chemistry 2015;166:522-530.

Haskard CA, Li-Chan ECY. Hydrophobicity of bovine serum albumin and ovalbumin determined using uncharged (PRODAN) and anionic (ANS-) fluorescent probes. Journal of Agricultural and Food Chemistry 1998;46:2671-2677.

Hatta H, Hagi T, Hirano K. Chemical and physicochemical properties of hen eggs and their application in foods. In: Yamamoto T, Juneja LR, Hatta $\mathrm{H}$, Kim M. Hen eggs: their basic and applied science. Boca Raton: CRC Press; 1997. p. 117-134.

Haugh RR. A new method for determining the quality of an egg. US Poultry Magazine 1937;39:27-49.

Havea P, Carr AJ, Creamer LK. The roles of disulphide and non-covalent bonding in the functional properties of heat-induced whey protein gels. Journal of Dairy Research 2004;71:330-339.

Hou H, Singh RK, Muriana PM, Stadelman WJ. Pasteurization of intact shell eggs. Food Microbiology 1996;13:93-101.

Laemmli UK. Cleavage of structural proteins during the assembly of the head of bacteriophage T4. Nature 1970;227:680-685.

Lang ER, Rha C. Apparent shear viscosity of native egg white. International Journal of Food Science and Technology 1982;17:595-606. 
Chaiyasit W, Brannan RG,

Chareonsuk D, Chanasattru W
Uzun $\mathrm{H}$, Ibanoglu E, Catal H, Ibanoglu S. Effects of ozone on functional properties of proteins. Food Chemistry 2012;134:647-654.

Virtanen JK, Mursu J, Virtanen HE, Fogelholm M, Salonen JT, Koskinen $\mathrm{TT}$, et al. Associations of egg and cholesterol intakes with carotid intima-media thickness and risk of incident coronary artery disease according to apolipoprotein E phenotype in men: the kuopio ischaemic heart disease risk factor study. American Journal of Clinical Nutrition 2016;103:895-901.

Wang G, Wang T. Effects of yolk contamination, shearing, and heating on foaming properties of fresh egg white. Journal of Food Science 2009;74:C147-56.

Woodward SA, Cotterill OJ. Texture and microstructure of heat-formed egg white gels. Journal of Food Science 1986;51:333-339.

Wu H, Wang Q, Ma T, Ren J. Comparative studies on the functional properties of various proteins concentrate preparations of peanut protein. Food Research International 2009;42:343-348.

Zayas JF. Gelling properties of proteins. In: Zayas JR, editor. Functionality of proteins in food. Berlin: Springer; 1997. p.310-366.

Plancken V, Van LA, Hendrickx ME. Changes in sulfhydryl content of egg white proteins due to heat and pressure treatment. Journal of Agricultural and Food Chemistry 2005;53:5726-5733. 
